\title{
8
}
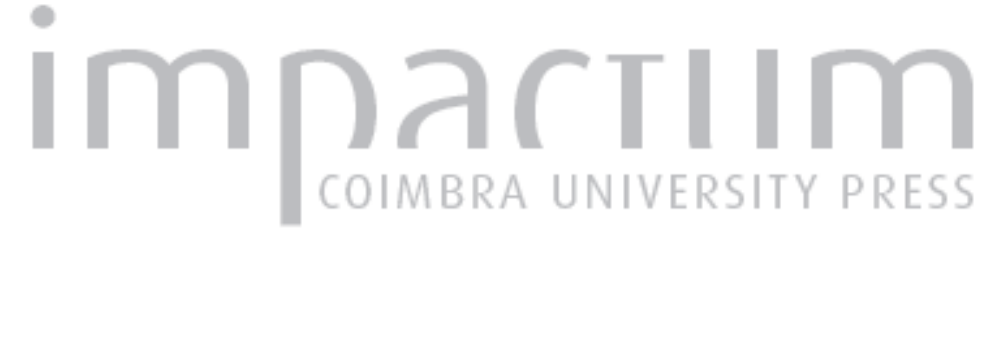

\section{[Recensão a] OSWALD SCHWEMMER, Das Ereignis der Form. Zur Analyse des sprachlichen Denkens}

Autor(es): Braga, Joaquim Publicado por: Faculdade de Letras da Universidade de Coimbra, Instituto de Estudos

URL

persistente:

DOI: $\quad$ DOl:http://dx.doi.org/10.14195/0872-0851_42_15

Accessed : $\quad$ 26-Apr-2023 09:02:36

A navegação consulta e descarregamento dos títulos inseridos nas Bibliotecas Digitais UC Digitalis, UC Pombalina e UC Impactum, pressupõem a aceitação plena e sem reservas dos Termos e Condições de Uso destas Bibliotecas Digitais, disponíveis em https://digitalis.uc.pt/pt-pt/termos.

Conforme exposto nos referidos Termos e Condições de Uso, o descarregamento de títulos de acesso restrito requer uma licença válida de autorização devendo o utilizador aceder ao(s) documento(s) a partir de um endereço de IP da instituição detentora da supramencionada licença.

Ao utilizador é apenas permitido o descarregamento para uso pessoal, pelo que o emprego do(s) título(s) descarregado(s) para outro fim, designadamente comercial, carece de autorização do respetivo autor ou editor da obra.

Na medida em que todas as obras da UC Digitalis se encontram protegidas pelo Código do Direito de Autor e Direitos Conexos e demais legislação aplicável, toda a cópia, parcial ou total, deste documento, nos casos em que é legalmente admitida, deverá conter ou fazer-se acompanhar por este aviso. 


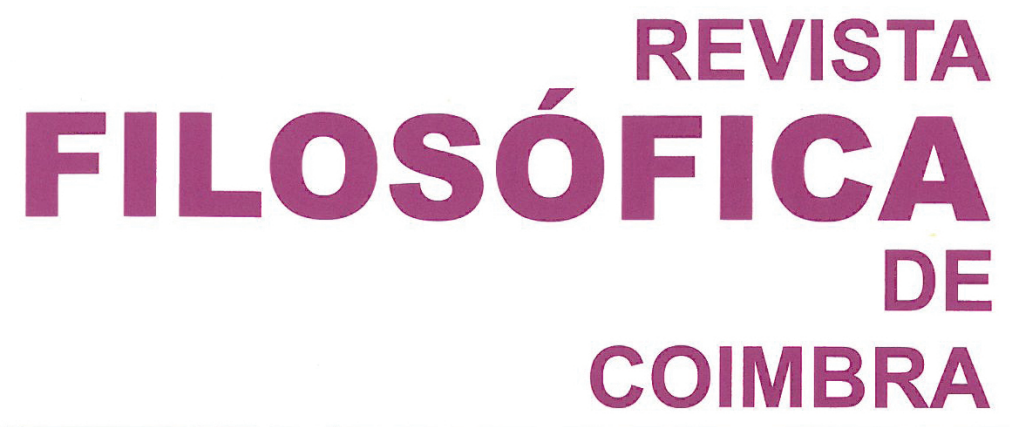

vol. 21 - número 42 - outubro 2012

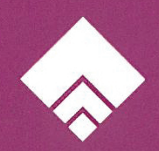


mente humana razão política, esta mais bem conhecida, e de efeitos deletérios mormente para a metafísica. E já agora, e mais problematicamente: o que responder a idêntica pergunta no campo da ciência? Sem querermos, nem podermos, acrescentar nada ao que tem sido feito e dito, sobre esta última, por exemplo por U. Baldini, por H. Leitão, por L.M. Carolino ou por B.M Mota, quer-nos parecer que, no tocante à filosofia, um horizonte possível de resposta deverá passar por examinar e estudar atentamente o chamado eclectismo. No nosso artigo em italiano supra citado, e a propósito de Luis António Verney e de um ponto preciso do seu labor (algo assim como um 'case study'), apontávamos esta corrente como uma das causas possíveis para a improdutividade histórica da filosofia que se fazia nas nossas fronteiras ou pela que era feita por portugueses além-fronteiras. Ora, quando J.P. Gomes opta por identificar as mais interessantes produções jesuítas como "eclécticas" (v.g. p. 160), ficamos com o seguinte dilema, que não saberíamos neste momento responder: ou esta caracterização da produção jesuíta é provisória e estudos mais profundos e aturados ajudar-nos-ão a torná-la mais fina e apurada ao ponto previsível do seu abandono - no que seria uma consistente atitude assaz digna da metodologia apenas aberta por J.P. Gomes - ou restar-nos-ia considerar aquela situação filosófica como inconsequente, verdadeira ou historicamente improdutiva e justificadora de uma qualquer intervenção regeneradora. $\mathrm{Ou}$, e seria afinal um trilema, o nosso entendimento do eclectismo é pobre; mas, nesta hipótese, o encontro de ambos os lados da barricada que se digladiavam com armas nem sempre elegantes, forçar-nos-ia a uma explicação mais espartilhadora de tal movimento filosófico até ao ponto crítico do seu esboroaramento. Não é que isso nos pareça mal, longe disso, mas seja qual for a resposta que vier a ser dada, uma só coisa é certa: ela só pode acontecer depois de termos sabido ser fiéis à silenciosa metodologia que J.P.Gomes praticou. É esta, decididamente, a memória que os organizadores desta oportuna selecta quiseram comemorar e pela qual deverão ser efusivamente cumprimentados.

Mário Santiago de Carvalho

OSWALD SCHWEMMER, Das Ereignis der Form. Zur Analyse des sprachlichen Denkens, München, Wilhelm Fink Verlag, 2011, 160pp.

Uma das premissas filosóficas fundamentais que atravessam a extensa obra de Oswald Schwemmer reflecte-se, mais uma vez, neste livro, a saber: a constatação da actividade simbólica do ser humano não deve desembocar numa mera análise mecanicista dos fenómenos que dela decorrem, já que é graças à contingência dos processos de mediação que são estabelecidos os nexos expressivos entre linguagem e interlocutores. Este trabalho da expressividade é, em rigor, uma condição necessária para a edificação da referencialidade do signo, mormente para a sua 
ligação a contextos de experiência. Uma reflexão filosófica sobre a intermutabilidade entre forma e expressividade já tinha sido aventada por Schwemmer em várias das suas obras. O que distingue o presente livro do filósofo da cultura é, sobretudo, o facto de ter recuperado o diálogo entre a filosofia cassireriana (Form) e o pensamento heideggeriano (Ereignis), iniciado, de modo bem explícito, nos estudos sobre o famoso debate de Davos (1929) entre os dois filósofos alemães (Enno Rudolph \& Dominic Kaegi [Hrsg.], Cassirer - Heidegger. 70 Jahre Davoser Disputation, Cassirer-Forschungen Band 9, Hamburg, Felix Meiner Verlag, 2001). Com este acoplamento entre Form e Ereignis, pretende o autor ultrapassar os obstáculos teóricos impostos pelas concepções internalistas e externalistas do pensamento linguístico, principalmente aquelas que se centram no primado das dimensões morfossintácticas da linguagem. É na articulação entre os elementos performativos e os elementos proposicionais das formas linguísticas que Schwemmer encontra um ponto de partida para a análise entre linguagem e pensamento. O "gesto" - elemento performativo na configuração dos actos discursivos - traz à reflexão a coexistência de um duplo movimento de exteriorização e incorporação do sentido mediado pela palavra, cuja fundamentação filosófica pode ser, por exemplo, vislumbrada na concepção heideggeriana da discursividade da "mão" (die Hand ist in einem mit dem Wort die Wesensauszeichnung des Menschen). O conceito de "forma" serve ao autor para dar consistência teórica à articulação entre os elementos performativos e os elementos designativos da linguagem, uma vez que a formação do sentido - tal como se define no pensamento cassireriano, e ao qual Schwemmer permanece fiel - não é dissociável do papel activo das estruturas sensíveis. Assim, a expressão Ereignis der Form deve ser compreendida como nomeação do processo que está na base dessa articulação. Um dos exemplos a que Schwemmer recorre para mostrar o processo de acoplamento entre Form e Ereignis é o de uma interacção familiar, cuja comunicação entre pais e filhos põe em relevo certos nexos de sentido, que, ancorados num jogo de percepções e de gestos afectivos, apresentam uma morfologia contextu$\mathrm{al}$, e, na distinção do autor, fazem parte da esfera "contingente" da significação (kontingente Bedeutung), pois a esfera "designativa" da significação (designative Bedeutung), embora nunca excluída dos processos de comunicação, deixa de ser o âmago da articulação dos conteúdos partilhados pelos interlocutores. É sob esta distinção que Schwemmer enceta uma crítica ao Tractatus de Ludwig Wittgenstein. Uma fundação expressiva da relação entre linguagem e pensamento não é redutível a uma análise positivista dos "factos linguísticos", quer esta seja realizada a partir das estruturas sintácticas da linguagem ou através de uma pretensa adequação lógica entre linguagem e mundo. Segundo a crítica incisiva do autor, a filosofia do Tractatus - assente num referencialismo designativo redunda em uma Digitalisierung avant la lettre (p. 52) das formas linguísticas. $\mathrm{O}$ estrato filosófico que envolve esta crítica personalizada nas primeiras concepções wittgensteinianas da linguagem, não subentende somente uma mera refuta- 
ção das teses positivistas, mas antes intenta alicerçar a ideia estruturante (tantas vezes esquecida pela análise das formas de mediação) de que a construção e a actualização do sentido comunicativo têm de ser concebidas como operações que põem em jogo várias dimensões polimórficas do sentido. De facto, e como bem exemplifica Schwemmer através da análise de uma configuração poética do autor alemão Stefan Popp, a relação entre pensamento e linguagem traz consigo vários campos semânticos extra-linguísticos, cuja pertinência teórica importa analisar e incluir no estudo sobre as formas de mediação. É desse modo, também, que o gesto - como metáfora representativa do Ereignis - pode continuar a ser visto como interpretação activa e simultânea da palavra, e não escassamente como sua manifestação passiva.

Joaquim Braga 